\title{
HISTÓRIA DE VIDA E PROFISSIONAL DA HISTORIADORA BRASILEIRA LAURA DE MELLO E SOUZA: INTERSECÇÕES ENTRE MEMÓRIA E BIOGRAFIA
}

\author{
LIFE AND PROFESSIONAL HISTORY OF THE BRAZILIAN \\ HISTORIAN LAURA DE MELLO E SOUZA: INTERSECTIONS \\ BETWEEN MEMORY AND BIOGRAPHY
}

DOI: http//dx.doi.org/10.15448/2178-3748.2017.1.20565

Carmem Silvia da Fonseca Kummer Liblik Doutoranda do Programa de Pós-graduação em História - UFPR carmemsfk@gmail.com

\begin{abstract}
RESUMO: O objetivo deste artigo é mostrar as relações entre história biográfica e memória na trajetória de vida e profissional da historiadora Laura de Mello e Souza. A articulação entre a memória feminina e biografia é tratada conforme seus relatos sobre a infância, a relação com familiares e amigos de profissão, as viagens realizadas, o ingresso na universidade e a conciliação entre a vida acadêmica e a maternidade. Quanto ao aspecto metodológico, tanto os recursos da história oral quanto da análise biográfica conduziram a pesquisa que teve como material fundamental uma entrevista concedida pela própria historiadora no dia 27 de setembro de 2013, em sua residência, na cidade de São Paulo.
\end{abstract}

PALAVRAS-CHAVE:Laura de Mello e Souza; Memória; Biografia.

ABSTRACT:The purpose of this article is to show the relationship between memory and gender in the life and professional course of the historian Laura de Mello e Souza. The relationship between the memory and gender is treated in conformity with her accounts of childhood, the relationship with family and friends in the profession, as well as trips made, the university entry and the hard conciliation of academic life with motherhood. Regarding the methodological aspect, both the resources of oral history and biographical analysis have conducted the research, founded on material obtained during an interview by the historian herself on September 27, 2013, at her residence in the city of São Paulo.

KEYWORDS:Laura de Mello e Souza. Memory. Biography.

Tratarei neste artigo da trajetória de vida e profissional da historiadora e professora universitária Laura de Mello e Souza que será problematizada por meio da correlação entre memória e biografia. Quanto ao aspecto metodológico, tanto os recursos da história oral quanto da análise biográfica conduziram a pesquisa que teve como material fundamental uma entrevista concedida pela própria historiadora no dia 27 de setembro de 2013, em sua 
residência, na cidade de São Paulo. ${ }^{1}$ Nesse sentido, ao elegermos a trajetória intelectual, profissional e biográfica da referida professora como objeto de discussão, as questões condizentes às relações de gênero acabam sendo vistas como elemento de análise de grande importância para o estudo. Tais questões estão presentes no interior das relações com seus pares profissionais e na inserção dela no campo profissional do historiador. O reconhecimento de que a sua trajetória intelectual e de vida foi circunscrita em relação às outras mulheres historiadoras e em relação aos homens - ou seja, dos seus pares profissionais - sugere uma análise de que o gênero pode ser um componente mediador das diferenças entre as carreiras construídas por homens e mulheres.

Um dos motivos principais que remetem à escolha desta profissional incide na natureza da minha pesquisa de doutorado que diz respeito ao mapeamento e análise das trajetórias de vida e profissional de historiadoras brasileiras no período de 1935 a 1990. A partir de dois contextos históricos específicos, quais sejam, a entrada das mulheres nos cursos de História a partir de 1935 e o processo de institucionalização da pesquisa histórica que se iniciou neste mesmo período, o qual contou com reformulações da prática e procedimentos do historiador, é possível realizar o mapeamento e analisar a vida, as práticas profissionais, as relações entre os colegas de trabalho, a conciliação entre casamento, maternidade e carreira e, sobretudo, a contribuição das mulheres historiadoras na historiografia brasileira e no desenvolvimento dos departamentos e cursos de História. ${ }^{2}$

Para tanto, a pesquisa visa a delimitação do período de 1935 a 1990, considerando o período inicial da entrada dessas mulheres nos cursos de História e, por extensão, a própria

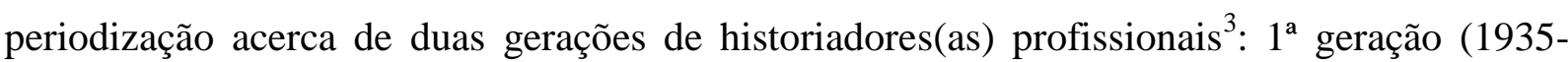
1970), responsável pela iniciação e consolidação das pesquisas históricas, objetos e procedimentos vinculados à História científica, bem como a consolidação das Cátedras e do trabalho dos assistentes; e $2^{\mathrm{a}}$ geração (1971-1990), responsável pelo início dos primeiros

\footnotetext{
${ }^{1}$ Expresso meus agradecimentos à professora Laura de Mello e Souza por ter concedido a entrevista e, sobretudo, pela leitura e conferência da transcrição da mesma.

${ }^{2}$ Consideraremos os primeiros cursos de graduação em História criados no Brasil, especialmente das regiões sul e sudeste, nas seguintes universidades públicas: UFF, USP, UFPR, UNICAMP, UFRJ, UFRGS, entre outros

${ }^{3}$ Os estudos geracionais, principalmente na antropologia brasileira, já contam com trabalhos como os de Debert (1999), Motta (2002), Simões (2004), Lins de Barros (1987), Eckert (1998), Riffioti (1998) e Peixoto (2000). Com a análise destes autores, pode-se perceber dois empregos distintos do termo geração como categoria analítica. No primeiro caso, indica-se a geração como posição no interior da estrutura de parentesco, relacionada à organização social do ciclo de vida. Em outro caso, no sentido mais mannheimiano do termo e com o qual pretendemos articular nesta pesquisa, a geração "designa um coletivo de indivíduos que vivem em determinada época ou tempo social, têm aproximadamente a mesma idade e compartilham alguma forma de experiencia ou vivência" (Motta, 2004).
} 
cursos de pós-graduação no país ${ }^{4}$, os quais voltaram-se também para novos olhares, temas, propostas metodológicas e extinção evolutiva das Cadeiras, além da constituição de produções acadêmicas mais regularmente organizadas e abertas para a ampliação do quadro de profissionais nas universidades. ${ }^{5}$

É nesta segunda geração que se encontra a historiadora Laura de Mello e Souza uma vez que ela concluiu o curso de História na USP em 1975 e trilhou sua carreira profissional ao realizar mestrado em 1980, doutorado em 1986 e livre docência em 1993. Há de se acrescentar que ela é docente do Departamento de História da Faculdade de Filosofia, Letras e Ciências Humanas da Universidade de São Paulo desde 1983 e foi a primeira mulher que passou a lecionar a disciplina de História Moderna nesta mesma instituição. Sua produção historiográfica incide em pesquisas sobre a história de Minas Gerais no século XVIII; sobre cultura, sociedade e política no império português nos séculos XVI-XVIII; sobre as relações entre a Europa e o Novo Mundo nos séculos XVI-XIX e sobre a historiografia brasileira do século XX. Ademais, ela desenvolveu ampla incursão profissional em países estrangeiros: foi Thinker Visiting Professor na Universidade do Texas (Austin, 1998) e professora visitante por curtos períodos na Universidade Nova de Lisboa, ICS/Universidade de Lisboa, Universidade de Minnesota, Universidade de Southampton, Universidade de Toronto, École des Hautes Études em Sciences Sociales, Universidade de Sevilha e Universidade Nacional do México. ${ }^{6}$

E por que recorrer à biografia? Para esta resposta trazemos uma reflexão do historiador Benito Schmidt: percebe-se que o retorno da biografia, pelo menos no âmbito da história, está inserido em um processo de profunda transformação das bases teóricometodológicas da disciplina. Como consequência, há uma reflexão sobre questões clássicas como a relação entre indivíduo e sociedade e especialmente as formas narrativas do conhecimento histórico (SCHMIDT, 2000a: 51). Cabe notar um aspecto significativo nesta abordagem: a historiografia estrangeira comprometida com o estudo sobre mulheres historiadoras, notadamente a inglesa, francesa e americana, privilegia sob o aspecto metodológico a biografia delas a fim de recompor suas trajetórias pessoais e profissionais. ${ }^{7}$

\footnotetext{
${ }^{4}$ Consideraremos os primeiros cursos de pós-graduação em História criados no Brasil nas seguintes universidades públicas: UFF (1971), USP (1971), UFPR (1972), UNICAMP (1976), UFRJ (1982), UFRGS (1986), entre outros.

${ }^{5}$ Naturalmente a atuação da primeira geração de historiadoras pode se sobrepor à segunda, uma vez que elas também participaram da criação dos cursos de pós-graduação. Logo, a delimitação empregada na periodização das gerações será utilizada especialmente no sentido de facilitar a abordagem das mudanças inerentes ao conhecimento histórico produzido nas universidades, nas quais elas estiveram presentes.

${ }^{6}$ Referências retiradas em seu Currículo Lattes no dia 28.01.2013: http://lattes.cnpq.br/7401949267772814

${ }^{7}$ A saber: SMITH, Bonnie. Gênero e História: homens, mulheres e a prática histórica. Bauru: EDUSC, 2003. PELLEGRIN, Nicole. Histoires d'historiennes. Publications de Lúniversité de Saint-Étienne, 2006. LOOSER, Devoney. British Women Writers and the Writing of History, 1670-1820. Baltimore: Johns Hopkins University
} 
Isto é, tal como nos estudos literários, ao analisar as obras de autores, há também nestas pesquisas uma preocupação com a trajetória biográfica e as experiências das historiadoras em questão, procurando explicar em que medida as suas vidas podem ter influenciado a composição de suas obras. Esta abordagem metodológica é muito profícua, uma vez que pouca atenção se dá aos possíveis nexos entre biografia do historiador e sua obra, e muito menos em relação ao estilo de escrita, figuras de linguagem que compõem o texto e temas escolhidos em pesquisas de pós-graduação. Isso vai em direção contrária aos estudos mais comuns e frequentes na historiografia: de modo geral, quando se trata de um historiador, vai-se direto apenas à obra avaliada e às transformações causadas no campo historiográfico e não às possíveis correlações com sua história de vida e lugares da subjetividade.

Já em relação à especificidade do tema - gênero como categoria mediadora da carreira entre homens e mulheres - utilizando recursos metodológicos baseados nas biografias, historiadores têm se dedicado a avaliar as condições de trabalho e às políticas de gênero inerentes aos institutos e universidades ligados às historiadoras de diversos países, como Estados Unidos, França, Canadá, Inglaterra, Rússia e Itália. Tinham elas as mesmas oportunidades que os homens historiadores? Como foi a relação com seus pares profissionais? De que forma elas construíram suas carreiras acadêmicas? Quais fatores concorreram para que seus trabalhos fossem aceitos? Como conciliaram a carreira com a vida pessoal e sobretudo familiar?

De modo geral, na entrevista concedida pela historiadora em questão a rede de memórias aparece de maneira significativa e é por isso que iremos problematizá-la no interior de sua trajetória de vida. Tentaremos, portanto, tecer considerações sobre a relação entre a memória feminina e a biografia histórica analisando relatos sobre a sua infância, a relação com os familiares e amigos, as viagens realizadas, o ingresso na universidade, o contato com as primeiras matérias e professores, o processo de fazer mestrado e doutorado, a conciliação entre a vida acadêmica e a maternidade, o concurso prestado para a carreira de professora e, por fim, sua trajetória como docente e pesquisadora. Como observa Ecléa Bosi, este registro alcança uma memória pessoal que, como se mostrará adiante, é também uma memória social, familiar e de grupo (BOSI, 1994: 10). Dessa maneira, em Laura é possível verificar uma história social bem desenvolvida: ela atravessou um determinado tipo de sociedade, com

Press, 2000. DES JARDINS, Juli. Women and the Historical Enterprise in America: Gender, Race, and the Politics of Memory, 1880-1945. Chapel Hill: University of North Carolina Press, 2003. DAVIES, Kate. Catharine Macaulay and Mercy Otis Warren: The Revolutionary Atlantic and the Politics of Gender. Cambridge: Cambridge University Press, 2005. 
características bem marcadas e conhecidas; teve também quadros de referência familiar e cultural igualmente reconhecíveis e distinguíveis.

É importante lembrar que a concepção da pesquisa situa-se na fronteira em que se cruzam os modos de ser do indivíduo e da sua cultura: no caso da professora Laura estamos nos referindo à cultura acadêmica e universitária atrelada à cultura de gênero. Finalmente, não é preciso dizer que na entrevista que realizei com a professora Laura, o motivo da pesquisa foi explicado com toda clareza à historiadora, e que ela teve autoridade sobre o registro de suas lembranças, memória e depoimento. Contaremos a escrita histórica no feminino, tendo lugar de observação a memória de uma historiadora, de sua própria leitura e interpretação do passado. Nosso interesse visa ao que foi lembrado, isto é, no que foi escolhido para perpetuarse em sua história de vida.

\section{Trajetória de vida e profissional de Laura de Mello e Souza}

Laura de Mello e Souza nasceu na cidade de São Paulo, em 1953. Filha de Antonio Candido e Gilda de Mello e Souza, ambos professores universitários da Universidade de São Paulo, diz que "nasceu dentro da Faculdade de Filosofia na rua Maria Antônia". Sobre sua infância, conta ainda que se lembra muito bem dela:

Eu me lembro muito bem, pois ficava frequentemente na portaria (da Faculdade) com uma funcionária enquanto mamãe ia cuidar das coisas dela.

Por parte da família materna, seu trisavô foi professor da Faculdade de Direito do Largo de São Francisco e tanto a mãe quanto os tios chegaram a concluir também curso universitário. Em relação à linhagem paterna, o quadro educacional não foi diferente. Mesmo tendo vindo do interior de Minas Gerais, seu avô se formou na Faculdade de Medicina do Rio de Janeiro. Foi o primeiro universitário da família dele. E é dessa forma que Laura conta o início de sua trajetória de vida, ou seja, lembrando e destacando o ambiente familiar atrelado à vida universitária que acompanhou a vida dos pais e demais parentes. Seria quase impossível, aqui, deixar de lado a interpretação da idéia de "memória geracional", observada muito bem por Joël Candau. Ela é também uma memória de fundação que tem seu lugar próprio no jogo identitário que, nesse caso, remete à identidade de "família de universitários". Em outras palavras, é a consciência de pertencer a uma cadeia de gerações sucessivas das quais o grupo ou o indivíduo se sente mais ou menos herdeiro (CANDAU, 2012: 142).

E esse é o caso da professora Laura, ou seja, sua memória e história de vida estão intimamente ligadas ao núcleo familiar que frequentou as salas de aulas de universidades 
brasileiras, como também lecionou nelas.A especialista em análise do discurso e crítica cultural, Leonor Arfuch, também reflete esta questão trazendo à luz a temática da genealogia no interior das biografias. Ou seja, nenhuma posição de enunciação advém "de graça” no espaço discursivo da fala do biografado: o desafio é justamente achar uma voz autobiográfica que possa dar sentido a um mito de origem, a uma genealogia, a um devir predestinado. Por isso, o espaço biográfico - a narração de histórias e experiências, a captação de vivências e lembranças - opera, completamente, nesse "resgate" do próprio local de origem (ARFUCH, 2010: 60). E, por extensão, Benito Schmidt também chama atenção para o fato de que em muitos trabalhos biográficos, é possível perceber que os autores buscam na infância e/ou na adolescência uma espécie de predestinação para suas atividades futuras (SCHMIDT, 2000a: 58). Como veremos no depoimento de Laura, é nítida a associação entre a escolha pelo curso de História e suas matérias preferidas com o ambiente cultural na qual estava inserida quando criança e adolescente.

Durante a infância e adolescência, Laura frequentou a casa da família de seu pai numa cidadezinha do interior de Minas Gerais. Suas lembranças acerca dessa época jorram luz em uma fase que girou em torno das "férias no interior, de histórias e de narrativas. Meu padrinho era um contador de histórias maravilhoso". Sua primeira experiência escolar, também contada logo no início da entrevista, ocorreu em Assis, cidade do interior de São Paulo, já que seu pai foi professor da Universidade Estadual Paulista "Julio de Mesquita Filho", Câmpus de Assis. Lá ficou durante um ano e meio, tempo correspondente à fase em que sua família morou na cidade. Em seguida, tendo retornado a São Paulo, foi matriculada em um colégio italiano, o Dante Alighieri, onde estudou até o segundo colegial e aprendeu a língua italiana que seria fundamental em sua vida universitária:

Eu estudei a vida inteira neste colégio. Ele foi muito importante na minha formação porque me ofereceu uma entrada para o mundo italiano que não é comum na universidade brasileira. Hoje em dia é mais (comum), mas naquela época não. Eu sempre fui ligada à historiografia italiana porque já tinha facilidade com a língua.

Mas os estudos foram interrompidos pois sua família precisou viajar e sair temporariamente do Brasil. O novo destino era a França, onde seu pai fora convidado para ministrar aulas na Sorbonne por um período de dois anos. Assim, depois que terminou o primário, Laura esteve com a mãe e a irmã mais velha em Paris. Chegou a estudar brevemente em uma escola francesa e, logo em seguida, teve a oportunidade de ir à Itália. Tinha somente doze anos quando ficou "vinte dias em Florença, vinte dias em Roma. Mais de dois meses 
viajando a pela Itália”. Mas a visita a países estrangeiros não parou por aí. Logo em seguida, nas férias, ela, a irmã e seus pais estiveram em Portugal e Espanha. Extraordinariamente, ao retornarem à França, seus pais acharam que não era mais o caso de ela ir à escola e então:

(...) eu fiquei em casa. Eu tive um ano completamente anárquico. (...) Mas por outro lado, para minha formação isso foi muito interessante porque eu tive que aprender a organizar o meu dia... eu não podia ficar assim... então eu tinha, aos 12 para 13 anos, total liberdade. Eu andava na rua sozinha o dia inteiro. Eu mesma fazia a minha programação.

Se por um lado não se lembra de ter ido ao cinema sozinha, por outro, ia sem companhia aos museus e igrejas. Explorava a cidade de Paris e costumava "brincar de turista". Ao refletir, hoje, sobre essas memórias, Laura conclui que sua "vocação se confirmou naquele ano anárquico de descobrir museus". No entanto, anos mais tarde, aos dezoito anos, a decisão de ter prestado exame para o curso de História não foi consciente, uma vez que estava em dúvida entre Medicina e Literatura. Mesmo assim, História foi o curso escolhido, apesar de que naquela época não sabia muito bem os reais interesses que motivaram essa decisão.

As viagens realizadas com os pais e a irmã, a autonomia de programar as atividades que teria ao longo do dia e o simples fato de andar na rua sozinha são indícios muito significativos que podem ser pensados à luz do conceito "sair" da historiadora Michelle Perrot. Esta autora observa que algumas mulheres ocidentais do século XIX souberam apoderar-se dos espaços públicos que antes não lhe eram permitidos. Essa ação foi um fator determinante no que diz respeito ao esforço de terem desejado aumentar sua influência no espaço público: terem ousado sair. Sair "fisicamente", penetrando em lugares "proibidos", como um café, um comício ou realizar uma viagem sem a companhia masculina. Mas há também outro sentido para o "sair". É o "sair moralmente", recusando os papéis que lhe eram atribuídos e buscando inserção no mundo do trabalho. Essas "saídas", portanto, podem ser referidas às viagens propriamente ditas, mas também ao trabalho, a "viagem-ação", através da qual as mulheres tentaram uma verdadeira "saída" para fora dos seus espaços e dos seus papéis (PERROT, 2005: 279-316).

E este é um dos aspectos históricos e culturais que marcam a geração ${ }^{8}$ de Laura. A partir da década de 1960, no Brasil, a empregabilidade feminina cresceria de forma sistemática tornando-se constante, intensa e diversificada. Mudanças comportamentais trazidas pelos movimentos feministas e de contra-cultura - alimentaram novas expectativas

${ }^{8}$ Ver nota explicativa n. ${ }^{\circ}$. 
femininas, despertando o desejo de autonomia financeira e de realização profissional nas mulheres das camadas médias. No entanto, conforme Francisco León, a empregabilidade feminina, entendida como a valorização do trabalho das mulheres e a disposição dos empregadores em contratá-las, era um objetivo central das reformas do mercado de trabalho processo este que não prescindia ser promovido. Portanto, inicialmente as atenções se voltaram para a obtenção da equidade no mercado de trabalho - ou seja, condições e salários idênticos para tipos idênticos de trabalho - entre trabalhadores de ambos sexos já empregados, e não em melhorar o acesso da mulher ao mercado de trabalho, especialmente, a postos de trabalho de qualidade. Contudo, na maioria dos países, o ingresso maciço da mulher no mercado de trabalho foi considerado como um processo, praticamente natural, dentro da etapa de desenvolvimento das sociedades latino-americanas (LEÓN, 2002: 11-12) Em relação ao acesso à educação, a expansão do ensino médio e universitário possibilitou a ampliação da escolaridade feminina em diferentes níveis e áreas de conhecimento. Entre 1970-1975, por exemplo, o número de mulheres nas universidades aumentou em cinco vezes, enquanto o de homens dobrou. $\mathrm{O}$ avanço da escolaridade entre as mulheres se ampliou nas décadas seguintes e gerou impacto no mercado de trabalho, tornando-as economicamente mais competitivas e capazes de enfrentar resistências e preconceitos e aumentar sua presença em setores até então impermeáveis ao feminino (MATOS \& BORELI, 2012: 142-145).

Nessa época Laura tinha apenas 12 anos. Mas o interessante é perceber que suas "saídas" tiveram continuidade na idade adulta, especialmente na vida acadêmica, porém de forma singularmente ousada e, paradoxalmente, tímida também. Mas como? Laura casou-se aos dezenove anos e no quarto ano da faculdade passou pela primeira gestação. A maternidade não lhe impediu de fazer o mestrado, tendo conseguido uma bolsa da FAPESP para a realização do mesmo. No entanto, conciliar os estudos com as obrigações da maternidade não foram fáceis, principalmente porque ela precisava viajar a fim de realizar sua pesquisa empírica. Essa situação é retratada como um momento muito difícil devido às circunstâncias das viagens realizadas e da fase inicial da pesquisa:

E eu, com a minha filha pequenininha, tinha que ir para Minas Gerais fazer minha pesquisa empírica. Ia de ônibus. Viajava a noite inteira de ônibus. Chegava em Minas, trocava de ônibus, pegava outro para Mariana e lá eu ficava num convento de freiras. Aí sim... eu acho que isso é interessante para você. Eu era muito jovem e tinha muito medo porque eu era sempre a única nos lugares. Eu me lembro que quando fiquei nesta hospedaria das freiras, entrava para comer de noite e tinha, assim, trinta homens jantando que trabalhavam numa companhia de mineração. E quando eu entrava, eles paravam de falar. Eu ficava muito constrangida. Eu levava uma comida, um negócio chamado bionorm que eu levava para o quarto para misturar com o 
iogurte. Era um pó, porque eu tinha vergonha de entrar nos bares ou nos restaurantes à noite em Mariana para comer. Então isso eu senti muito porque sempre fui muito autônoma. Tinha muito medo, era muito tímida. As coisas eram bem diferentes de hoje em dia. Apesar de 1968, da minha geração... viajar era complicado... mulher estar lá fazendo pesquisa, com 23 anos de idade.

Nesta fala pode-se examinar a maneira pela qual as crises pessoais de um indivíduo refletem as tensões de uma época, ou como a historiadora Mary del Priore diz, "como as soluções pessoais do conflito fazem eco, se apropriam ou se impregna de uma cultura" (PRIORE, 2009: 7-16). Centrar as análises sobre os indivíduos, suas paixões, constrangimentos e representações que pesavam sobre suas condutas é um dos aspectos mais importantes que aparecem nas biografias tecidas por esta historiadora. Isto é, não tem como pensar o indivíduo e suas ações não situando-o em relação ao ambiente social ou psicológico, a sua educação e experiência profissional e, neste caso especialmente, a sua cultura de gênero. É evidente que a igualdade educativa entre os sexos foi conquistada através da criação de escolas e universidades laicas e mistas, mas, no entanto, isso não facilitou a inserção das mulheres no mercado de trabalho, ou como no caso de Laura, a realização de pesquisas em espaços notadamente masculinos. Ainda haveria muitas dificuldades por parte de mulheres historiadoras de realizarem suas pesquisas de pós-graduação, uma vez que a maternidade e a necessidade de realizar viagens foram circunstâncias que elas precisaram contornar para atingir seus objetivos profissionais.

Se por um lado houve dificuldades para prosseguir os estudos após o término da graduação, por outro a historiadora não silencia certas facilidades, ou "sorte", como prefere chamar, decorrentes da tradição acadêmica do núcleo familiar. Tanto seu avô quanto seu pai tinham uma biblioteca na qual havia muitos livros de história. Vários deles, que por sinal ela possui até hoje guardados nas prateleiras de sua biblioteca, foram dados por Antonio Candido. Ainda quando jovem, costumava ler a história da França e da Inglaterra, bem como os clássicos da literatura como William Shakespeare, Charles Dickens e Alexandre Dumas. Sem sombras de dúvidas ela estava imersa num ambiente muito propício para a leitura, erudição e pesquisa. Por extensão, quando entrou na universidade, Laura já falava três línguas: inglês, francês e italiano.

Este contexto, atrelado também aos fatos de ter estudado em um colégio italiano, de ter tido um tio que narrava histórias e de ter viajado para fora do Brasil quando criança, remetem ao que David Lowenthal desenvolve sobre a maneira como conhecemos o passado. Para este autor, não temos muita consciência da maioria dos "resíduos do passado" de nossa 
história de vida. Mas, é possível atribuir significado a eles conforme o momento presente: esse esforço consciente é necessário para reconhecer que muito do que vivemos hoje advêm do passado. Na verdade, temos consciência do passado como um âmbito que coexiste com o presente ao mesmo tempo que se distingue dele (LOWENTHAL, 1998: 64-65).

Questionada sobre como foi sua graduação, Laura nos informa que foi uma "aluna medíocre no primeiro ano e achava muito difícil a História Antiga". No entanto, adorou História Medieval, pois teve um grande e excelente professor, Pedro Moacir Campos. Chegou até a ministrar, mais tarde, uma disciplina de História Medieval ao substituir seu colega e querido amigo Hilário Franco Junior, na Faculdade Moema, quando ele fez seu doutorado na Espanha. E assim, paulatinamente, a historiadora reúne elementos para explicar porque sentiu afinidade com esta disciplina, rememorando novamente o período em que morou na França quando criança:

Eu gostava muito da disciplina pois tinha morado na França e gostava da Idade Média francesa. Tenho um baralho, comprado por meu pai na França, que foi uma coisa importantíssima na minha vida. É um baralho que você tem que casar os reis da França. Ele é lindo e às vezes, até hoje, eu vou trocando os pares.

Laura se levanta e vai ao encontro da caixinha onde estava guardado o famoso baralho. De fato, é um objeto singular, típico e muito pessoal. Imediatamente lembramos nesse momento o que Candau diz sobre o "poder dos traços”, que é encontrado na predileção que os indivíduos podem manifestar por objetos ou lugares que recordam seu passado (CANDAU, 2012: 160). O indivíduo se liga a um objeto particular e nele deposita sua memória, identidade e origens pessoais, familiares e sociais. Todos esses signos memoriais servem para veicular informações ou ativar a lembrança sobre acontecimentos, bem como afirmar o caráter durável do laço familiar.

Além do professor Pedro Moacir Campos, Laura referencia também Maria Odila Leite da Silva Dias e Anita Novinski como professoras emblemáticas que lecionaram disciplinas pelas quais ela se encantou. Foi com Maria Odila que ela leu, pela primeira vez, Thompson e Hobsbawm e era frequente em suas aulas a formação de grupos em que as "leituras eram maravilhosas". Já a historiadora Anita Novinski, "era uma mulher linda, apaixonadíssima. Ela também falava muito da História das Mentalidades e foram os dois que abriram para a gente esta porta”. Mas quem era a segunda pessoa? Laura se refere, então, ao seu professor de História Moderna e futuro orientador, o historiador Fernando Novais. Sobre as aulas assistidas, ela diz: 
Foi um curso extraordinário. Foi ali que aprendi a estudar, aprendi a conhecer bibliografia toda... era um curso de História Moderna mas é... a aula expositiva era uma conferência sobre o programa canônico. Mas o seminário, ele misturava muito. Então a gente lia história da arte. A gente lia Gilberto Freyre. E isso foi muito importante para a minha formação. Li Foucault com ele. Li Paul Hazard, que foi um autor muito importante. Robert Mandrou. História das Mentalidades fiz com ele.

Mais do que um grande professor na graduação, Fernando Novais mostrou-se também um orientador muito próximo e solidário com as dificuldades pessoais enfrentadas por Laura:

Ninguém mais doce e mais querido do que ele. (...) Às vezes eu chegava lá meio chorando: "ah professor, eu estou grávida de novo". E ele dizia: "imagina, você vai lá para casa e eu cuido de seu neném". Outro dia ele falou: "lembra Laura, que você ia lá para a casa com a Dorinha e, enquanto você falava, eu ficava andando com ela pela casa no colo". É verdade! A maior solidariedade e o maior apoio. Ele nunca veio com o comentário de qualquer tipo. O lado humano dele como orientador sempre foi espetacular. Ele sempre aproximou os colegas, gostava que seus orientandos fossem amigos. Ele era solidário, compreensivo. Às vezes eu falava: "professor, eu não vou conseguir", e ele falava "você vai conseguir, Laura".

Nesta fala, como em outras que pudemos elencar até então, observa-se um terreno que desafia os limites da ego-história: trazemos à luz um lugar da subjetividade do historiador que remete aos sentimentos, afetos, amizades que perpassam as fronteiras da sala de aula, enfim, tudo o que diz respeito ao mundo interior que dialoga com tensões, contradições e emoções. Ao lado disso, novamente o tema da maternidade é trazido ao seu depoimento. Natural e paulatinamente esta questão aparecia no interior dos fatos, situações e conversas lembradas por Laura. Mas aparecia também porque a própria dinâmica da entrevista permitia isso, ou seja, com alguma frequência eu acenava o tema no interior das perguntas feitas a ela. Era uma via de mão dupla. Neste caso, questionei como foi sua relação com seu orientador de mestrado e doutorado e como ele lidou com as suas duas gestações. Na verdade, ela teve três, sendo que a primeira ela teve, como informado antes, no final da graduação.

Como afirma Alessandro Portelli, a história oral só se completa na transformação em história escrita. Nessa escrita, nós enquanto pesquisadores estamos irremediavelmente entrelaçados ao tema, pois somos nós que fazemos as escolhas das falas e as interpretações daí decorrentes. Em outras palavras, existe muito de nós na interpretação que damos aos fatos e relatos que colhemos. E é importante ter consciência desse papel. Interessa-nos a seguinte afirmação de Portelli: "não há historia oral antes do encontro de duas pessoas diferentes, uma com uma estória para contar e a outra com uma história para reconstruir" (PORTELLI, 2001: 18). Nesse ponto, cumpre lembrar outra afirmação deste autor quando enfatiza que " $a$ 
história oral se inicia na oralidade do narrador, mas é encaminhada (e concluída) em direção ao texto escrito do historiador" (PORTELLI, 2001: 13).

Provavelmente a primeira gestação foi uma das fases mais difíceis em relação à vida acadêmica. Laura comenta subitamente: "olha outro episódio, veja como as coisas vão aparecendo". E o episódio diz respeito à última disciplina de Licenciatura que ela precisava concluir na graduação, mas que foi dificultada por um empecilho movido por uma professora. Nesse ponto, é inevitável incluir nesta análise as dificuldades impostas pelas próprias mulheres, umas às outras, principalmente quando se trata de crescimento profissional. Naturalmente que não se pode generalizar, mas em muitos relatos orais realizados nesta pesquisa é evidente a colocação de historiadoras que conviveram com antigas professoras que não aceitavam uma possível conciliação entre a vida intelectual, maternidade, vida pessoal e familiar:

Eu falei para a professora que eu estava grávida, terminando o bacharelado, e que ficou faltando a matéria de licenciatura. Eu estava grávida e minha filha nasceu no dia 5 de junho. Aí eu cheguei para a professora no começo do semestre e falei... e olha que era uma mulher, hein?! Falei: eu estou grávida e talvez a criança nasça antes do fim do curso. Ela tratava muito mal as meninas, essa professora. A minha filha nasceu no dia 5 de junho e eu perdi os outros dias desse mês. Ela me reprovou. Aí eu tive que voltar, com a minha filha pequenininha, pois era uma disciplina que só tinha no primeiro semestre. Eu tive que voltar em outro ano e fazer à noite, se me lembro bem. Nem me lembro de como eu fiz. Sei que ela era pequenininha, a deixava em casa e então ia fazer prática de ensino.

É nesse sentido que a professora Laura constrói sua narrativa, tecendo os fios das lembranças, as quais se misturam, se organizam de maneira não linear e se somam de forma que um acontecimento, uma pessoa ou um afeto conduzem à memória de outros eventos que lhes são importantes. Michael Pollak enfatiza o fato de que as histórias de vida, como esta que estamos problematizando, podem ser consideradas um instrumento de reconstrução da identidade. Isso porque elas ordenam acontecimentos que sustentaram uma existência. Mas o mais importante é notar que Pollak parece não se importar tanto com o fato de tentarmos organizar o passado numa lógica coerente. Ao contrário, é por meio do trabalho de reconstrução que o indivíduo acaba definindo o seu lugar social e suas relações com os outros. Se notamos que os depoentes buscam desenvolver uma lógica linear e racional em seus relatos, é verdade também que esta é logo “perturbada” pelas suas próprias reflexões e pelos intrincados caminhos da memória (POLLAK, 1989: 3-15). Ao mesmo tempo, como afirma Benito Schmidt, é nítida a preocupação de se construir uma identidade estável para os 
personagens, entendida como constância em si mesmo de um ser previsível ou, no mínimo, inteligível, à maneira de uma história bem construída (SCHMIDT, 2000b: 59).

E esses caminhos, com certa frequência, levam a determinados lugares e grupos de pessoas que lhes muito são caros. A recepção da Faculdade de Filosofia e Letras, a biblioteca do pai, os museus, as igrejas e, especialmente, a USP constituem a topografia central abrigada pela memória da professora Laura. Orgulha-se de ter feito todos seus estudos, incluindo a livre docência, na USP. "Eu fiz toda minha formação na universidade brasileira, coisa da qual me orgulho muito". Quando está fora do Brasil, frequentemente lhe perguntam onde ela se formou. Responde ela categoricamente: na Universidade de São Paulo.

Quanto ao grupo de amigos com que teve contato na universidade, ela lembra daqueles que lhe eram mais próximos. Era uma turma na qual predominava a clientela feminina. "Era mais mulher e o corpo docente era mais mulher também. E hoje em dia é ao contrário". Os amigos Nicolau Sevcenko, Maria Inez Machado Borges Pinto, Leila Mezan Algranti e Elias Saliba aparecem em sua fala:

$\mathrm{Na}$ minha turma predominavam mulheres. Foi uma turma incrível, incrível. A minha turma tinha a Leila Mezan, a Sheila Schvarzman que depois seguiu carreira, fez doutorado, mestrado na UNICAMP. Foi casada com o irmão da Leila, o Renato Mezan. O Elias Saliba, meu colega; Nicolau Sevcenko que não é só um colega mas um grande amigo que acabou dividindo sala comigo. Dividimos sala durante vinte anos e entramos no mesmo concurso. Ele tirou o primeiro lugar e eu tirei o segundo. Maria Inez Machado Borges Pinto que inclusive morou comigo alguns meses. Eu já era casada, tinha um apartamentinho, não tinha filhos, então ela morou lá alguns meses. Quem mais era da minha turma que seguiu carreira? Não me lembro agora, mas vai acabar vindo. Mas era uma turma muito boa. Acho que era mais mulher.

De maneira geral, as primeiras turmas do curso de História da região sul e sudeste foram cursadas predominantemente por mulheres e esse fato se explica pela política federal de comissionamento. Historicamente, a possibilidade de acesso mais expressivo das mulheres nas universidades públicas se deu efetivamente a partir da década de 1930. Foi um período importante, no qual foi instituído o Decreto $\mathrm{N}^{\circ} 19.851$, de 11 de abril de 1931 - proposto pelo Ministro Francisco Campos - cujo objetivo elementar dizia respeito à reforma do ensino superior, constituindo assim um dos motivos a suscitar o surgimento das Faculdades de Filosofia, Ciências e Letras (FFCL) no país, uma vez que a anterior formação de profissionais em nível superior no Brasil estava limitada às áreas de Medicina, Direito e Engenharia ${ }^{9}$. A

\footnotetext{
${ }^{9}$ Trata-se de uma reforma que buscava organizar o Ensino Superior dentro de uma noção de autonomia relativa das instituições de ensino. Suas diretrizes previam que todas as instituições de Ensino Superior, para se constituírem como Universidade, necessitavam estar compostas por no mínimo três das quatro faculdades:
} 
partir desta data e nas décadas posteriores, ingressar na Universidade de São Paulo, na Universidade do Rio de Janeiro, na Universidade do Paraná, na Universidade do Rio Grande do Sul, dentre outras universidades públicas, portanto, significava inserir-se num espaço público, misto, fora do restrito controle moral imposto pela religião e pelas famílias, no qual as mulheres estariam expostas à influência de um ambiente intelectual laico e à convivência com jovens de origens sociais e culturais múltiplas.

A aquisição dos diplomas superiores deu-se predominantemente nos cursos voltados para receber a clientela feminina, tais como Letras, Pedagogia, Psicologia, História, Serviço Social e Belas-artes. Conforme o estabelecimento do Decreto $N^{\circ} 19.851$, tais cursos possuíam em comum o fato de formar professores qualificados para o ensino primário e secundário, e nos anos seguintes também fornecer profissionais para o ensino superior. Conforme a historiadora Alice Canabrava, muitas mulheres que frequentaram a USP, quando de sua criação em 1934, puderam fazê-lo através do comissionamento. As mulheres foram as que mais entraram para a USP por este mecanismo, pois elas constituíam a maioria das professoras primárias. Eram mulheres que trabalhavam, não tinham posse, de modo geral dependiam de seus salários e para poder frequentar uma faculdade não podiam abrir mão do salário (CANABRAVA, 2004: 87-88).

Perpassando a ideia da memória como tal, sugerimos compreender esta questão à luz do conceito de "quadros sociais da memória", do sociólogo Maurice Halbwachs. Nessa direção, as relações sociais a serem determinadas não ficam atreladas apenas ao mundo pessoal e familiar dos sujeitos, uma vez que elas estão ligadas à realidade das instituições sociais. Nesse sentido, a memória do indivíduo depende do seu relacionamento com a família, com a classe social, com a escola, com a Igreja e com a profissão: enfim, com os grupos de convívio e os grupos de referência peculiares a esse indivíduo (HALBWACHS, 2006). Os principais amigos de graduação de Laura formam um grupo especial que permanece em sua memória até hoje, sobretudo porque seguiram a vida acadêmica depois de finalizada a graduação.

Ademais, é notável a presença de amigos homens em sua rede de sociabilidade, tanto por parte de seus colegas de turma quanto a amizade que nutriu com o próprio orientador. $\mathrm{O}$ relato desta historiadora de que a amizade mista no meio acadêmico e profissional pode existir, não pode ser ocultada. A historiadora Ana Paula Vosne Martins já nos lembrou desta

Faculdade de Medicina, Faculdade de Direito, Faculdade de Engenharia e Faculdade de Filosofia, Ciências e Letras. É a partir deste decreto que surgem as primeiras Faculdades de Filosofia, Ciências e Letras, nas quais aparecem os primeiros cursos de História e Geografia. 
questão em seu artigo "Da amizade entre homens e mulheres: cultura e sociabilidade nos salões iluministas". Neste artigo, a autora propõe que foi pela amizade que homens e mulheres modernos começaram a romper as distâncias culturais de gênero que os colocavam em mundos paralelos (MARTINS, 2007: 51-67). No caso da professora Laura, a amizade com historiadores não foi somente possível, mas importante em sua trajetória acadêmica e profissional.

Sobre os aspectos profissionais, ela relata que não chegou a planejar sua carreira da mesma forma que os historiadores fazem atualmente devido à acirrada competição que existe no meio acadêmico. Contudo, os motivos que explicam à falta de planejamento profissional no passado condizem, sobretudo, às questões pessoais e de ordem familiar:

Não cheguei a planejar a minha vida profissional. Eu gostaria de fazer como vários da minha geração fizeram. Meu sonho era ter terminado a faculdade e ter ido embora. Ter ido para a França, para a Inglaterra estudar. Mas aí eu casei. Não tive frieza para dizer "não, não vou casar pois prefiro fazer carreira". Eu preferi casar e ter filho. Então são as escolhas que a gente faz na vida. Não me arrependo de nada mas é tudo mais complicado. (...) Para mim, foi tudo acontecendo.

É evidente, não só nesta passagem como em outras também, um grande e importante embate relacionado aos papéis de gênero. Ou seja, de certa maneira, podemos dizer que Laura rompe com os binarismos vinculados aos papéis que homens e mulheres deveriam cumprir. Mas, se por um lado ela decidiu realizar um curso universitário, especializar-se no mestrado e doutorado, prestar concurso para a carreira de docente em uma universidade, estabelecer amizades com historiadores, "sair" como diz Michelle Perrot, por outro, ela enfrentou as contingências de gênero existentes em sua época. E uma destas contingências diz respeito aos próprios lugares que as mulheres tiveram que assumir historicamente: o lugar da família, do cuidado, da maternidade e do lar. E é com esse exemplo que podemos entender o que Benito Schmidt afirma sobre a construção de uma trajetória pessoal: buscamos a possibilidade de entender um pouco a história do tempo em que o personagem viveu, sendo possível estabelecer uma articulação entre as trajetórias estudadas e os contextos onde elas se realizaram (SCHMIDT, 2000a: 55-56). E o contexto histórico que permeou a vida de muitas mulheres da década de 1970 adiante foi justamente do embate e das dificuldades de superação da conciliação entre carreira e estudos com a vida privada.

No caso de Laura, a família, e em especial a maternidade, constituem por excelência outros empreendimentos da vida onde ela também direcionou todos seus esforços e desejos, mesmo com muitas dificuldades. Lugares fixos e subjetivos que pertencem à mulher: eis um 
universo que é completamente borrado nesta história de vida. Observamos uma vasta complexidade das representações modernas do feminino e do masculino na trajetória desta profissional. Por isso tal exemplo no traz uma reflexão muito importante sobre as linhas que compõe o sujeito, as camadas que nos cobrem, mas que não são fixas, pois uma desliza sobre a outra, configurando, assim, um novo entendimento sobre a subjetividade contemporânea e especialmente aquela que diz respeito às mulheres.

O que explica a determinação de iniciar um curso superior ainda quando jovem e trilhar uma carreira universitária em uma das maiores e mais respeitadas universidades do país? Ainda mais considerando um ambiente androcêntrico em que a figura do intelectual é quase sempre vinculada ao ser masculino? É evidente que esta questão não se aplica somente ao caso de Laura, e sim a outras historiadoras pioneiras como Alice Piffer Canabrava, Maria Yedda Linhares, Eulália Maria Lahmeyer Lobo, Maria Odila Leite da Silva Dias, entre outras. Aqui nos aproximamos da ideia de "ambição feminina", projetada pela historiadora Elisabeth Badinter. Para ela, desde o período moderno a ambição não cabia às mulheres. Tudo o que se refere à ambição é símbolo de virilidade. "Combater", “dominar", "conquistar" pertencem ao vocabulário guerreiro pouco compatível com a imagem da mulher. $\mathrm{O}$ ambicioso quer desafiar a necessidade e se colocar acima da natureza, enquanto a mulher está imersa nesta com a ordem de aí permanecer. Mas o objetivo de Badinter, então, é estudar especificamente a ambição feminina, propiciada por determinados momentos políticos e culturais (BADINTER, 2003: 29-30). E Laura, ao nosso ver, possuiu essa determinação que a encorajou a prosseguir, mesmo contando com as mais variadas dificuldades. Sobre isso, ela depõe:

Sentia dificuldade, mas eu sentia sobretudo que eu não podia capitular, que era uma questão de honra. Porque todo mundo dizia: "você não vai conseguir. Você vai ter outro filho? Você é louca. Agora a tua carreira acabou".

Ao final deste artigo, queremos lembrar que nos trabalhos biográficos, evidentemente o uso de uma trajetória de vida não pode representar um grupo; cada trajetória tem um valor próprio. Cada pessoa é única e sua inserção social se dá a partir de várias questões. Contudo, ao mesmo tempo, as experiências grupais também se manifestam em cada indivíduo. É exatamente esse processo de análise que possibilita uma conexão entre a subjetividade individual e o social. Em suma, queremos trazer à luz neste ensaio, uma ideia que Benito Schmidt defende: os biógrafos não devem se fixar na busca de uma coerência linear e fechada para a vida de seus personagens, mas que precisam sim apreender facetas variadas de suas existências, transitando do social ao individual, do inconsciente ao consciente, do 
público ao privado, do familiar ao político, do pessoal ao profissional, e assim por diante, sem tentar reduzir todos os aspectos da biografia a um denominador comum (SCHMIDT, 2000a: 63). Sem sombra de dúvidas que este tipo de trabalho torna-se mais difícil quando se trata de reconstruir uma trajetória biográfica de intelectuais e professores universitários. Se pensarmos nas reflexões mantidas pela ego-história, entenderemos o porquê: nela, a audiência não é qualquer leitor, mas os pares, os profissionais que compartilham da mesma ocupação, referenciais teóricos e redes de relações. Por isso, na ego-história, é ausente qualquer tipo de autorreflexão que contenha dimensões íntimas (WILTON, 2012: 39-61). E isso não foi exatamente o que procuramos tecer na biografia da professora Laura. Pelo contrário.

Quanto à própria entrevista, queremos notificar o fato de que uma historiadora falando para outra historiadora facilitou esse processo. A proximidade de gênero e de contexto educacional nos aproximou e possibilitou momentos de compartilhamento. Contudo, é justo também destacar que essa mesma proximidade tem dois lados. São pessoas falando para um público - de historiadores, que as conhecem e isso também pode criar um nível de expectativas e preocupações em ambos os lados. Dizer que todas essas arestas foram aplainadas seria falso. O que posso dizer é que tentamos ao máximo construir esse difícil lugar entre a confiança, a proximidade e distância necessária. Tanto a entrevista quanto a transcrição decorrente, bem como a reconstrução histórica e biográfica foram um processo de aprendizado inextinguível.

\section{Referências Bibliográficas}

ARFUCH, Leonor. O espaço biográfico: dilemas da subjetividade contemporânea Rio de Janeiro, EdUERJ, 2010.

BADINTER, Elisabeth. Émile, Émile. A ambição feminina no século XVIII. São Paulo: Discurso Editorial: Duna, Dueto. 2003.

BOSI, Ecléa. Memória e sociedade: lembrança de velhos. São Paulo: Companhia das Letras, 1994.

CANABRAVA, Alice. O caminho percorrido. In: BLAY, Eva; LANG, B. S. G. Mulheres na USP: Horizontes que se abrem. $1^{\text {a }}$. ed. São Paulo: Humanitas, 2004.

CANDAU, Joël. Memória e identidade. São Paulo: Contexto, 2012.

DEL PRIORE, Mari. Biografia: quando o indivíduo encontra a história. Topoi. v. 10, n. 19, jul.-dez. 2009.

HALBAWACHS, Maurice. A memória coletiva. São Paulo: Centauro, 2006. 
LEÓN, Francisco. O novo padrão de participação feminina na América Latina. In: LAVINAS, Lena; LEÓN, Francisco. Emprego feminino no Brasil: mudanças institucionais e novas inserções no mercado de trabalho. Vol. 1. CEPAL, Publicación de las Naciones Unidas: Santiago de Chile, 2002.

LOWENTHAL, David. Como conhecemos o passado. Projeto História (17). São Paulo: EDUC, nov. 1998.

MARTINS, Ana Paula. Da amizade entre homens e mulheres: cultura e sociabilidade nos salões iluministas. História, Questões e Debates. Curitiba: Editora UFPR, v. 46, 2007.

MOTTA, Alda Brito da. Gênero, idades e gerações.Cadernos CRH. Set./dez. Salvador. Vol. $17, \mathrm{n}^{\circ} 42,2004$.

PEIXOTO, C. E. Envelhecimento e imagem: as fronteiras entre Paris e Rio de Janeiro. São Paulo: Annablume, 2000.

PERROT, Michelle. As mulheres ou os silêncios da história.Bauru, SP: EDUSC, 2005.

PORTELLI, Alessandro. História oral como gênero. In:Projeto História: Revista do Programa de Estudos Pós-Graduados em História e do Departamento de História da PUC-SP, n 22 (História e oralidade). São Paulo: EDUC, 2001.

MATOS, Maria Izilda; BORELLI, Andrea. Espaço feminino no mercado produtivo. PINSKI, Carla B; PEDRO, Joana M. In: Nova História das mulheres. São Paulo: Contexto, 2012.

POLLAK, Michael. Memória, esquecimento, silêncio.Estudos Históricos. Rio de Janeiro: CPDOC-FGV, v. 2, n. 3, 1989.

SCHMIDT, Benito. Luz e papel, realidade e imaginação: as biografias na história, no jornalismo, na literatura e no cinema. In: SCHMIDT, Benito Bisso (org.). O biográfico: perspectivas interdisciplinares. Santa Cruz do Sul: UNISC, 2000a.

"A Biografia Histórica". In: GUAZELLI, César A.B.; PETERSEN, S.R.F, SCHMIDT, B.B.; XAVIER; R.C. (org.) Questões de Teoria e Metodologia. Porto Alegre: Editora da UFRGS, 2000b.

WILTON, C.L. SILVA. Espelho de palavras: espelho de si, autoetnografia e ego-história. In: AVELAR, Alexandre de Sá; SCHMIDT, Benito Bisso. Grafia da vida: reflexões e experiências com a escrita biográfica. São Paulo: Letra e Voz, 2012.

ARTIGO ENVIADO EM: 06/05/2015

ARTIGO ACEITO PARA PUBLICAÇÃO EM: 15/06/2015 